\title{
Anti-inflammatory Effects of Indomethacin's Methyl Ester Derivative and Induction of Apoptosis in HL-60 Cells
}

\author{
Su-Hui Chao, ${ }^{a}$ An-Bang Wu ${ }^{a}$ Chia-Jung Lee, ${ }^{a} \mathrm{Fu}-\mathrm{An}$ Chen, ${ }^{b}$ and Ching-Chiung Wang$*, a$ \\ ${ }^{a}$ School of Pharmacy, College of Pharmacy, Taipei Medical University; 250 Wu-Hsing Street, Taipei 11031, Taiwan: and \\ ${ }^{b}$ Department of Pharmacy, Tajen Institute of Technology; 20 Wei-Shin Road, Yan-Pu Shiang, Pingtung 907, Taiwan. \\ Received July 7, 2005; accepted September 2, 2005
}

\begin{abstract}
Indomethacin is used as an anti-inflammatory drug and a nonselective cyclooxygenase inhibitor. When indomethacin in methanol was photo-irradiated with an $\mathbf{H g}$ lamp, methyl ester, ethyl ester, and $\gamma$-lactone derivatives of indomethacin were produced. In the present study, we found that the methyl ester derivative of indomethacin (M-IN) could more potently inhibit prostaglandin $\mathrm{E}_{2}\left(\mathrm{PGE}_{2}\right)$ and nitric oxide (NO) production and inducible nitric oxide synthase (iNOS) and cyclooxygenase 2 (COX 2) protein expression from lipopolysaccharide (LPS)-stimulated RAW 264.7 cells than indomethacin, similar to the effect of a non-steroidal anti-inflammatory drugs (NSAID). On the other hand, the results showed that $\mathrm{M}-\mathrm{IN}$ with an $\mathrm{IC}_{50}$ value maintained at $36.9 \mu \mathrm{g} / \mathrm{ml}$ for $12 \mathrm{~h}$ exhibited stronger cytotoxicity than ethyl ester, $\gamma$-lactone derivatives of indomethacin, and indomethacin in promyelocytic leukemia HL-60 cells. Moreover, a series of biochemical analyses determined that M-IN caused apoptotic bodies, DNA fragmentation, and enhanced PARP and pro-caspase 3 degradation in HL-60 cells. These above results indicate that the photosynthesized product, M-IN, had stronger anti-inflammatory effects in LPSstimulated RAW 264.7 cells and cytotoxicity effects in HL-60 cells than the parent drug, indomethacin.
\end{abstract}

Key words anti-inflammatory drug; cyclooxygenase; apoptosis; caspase 3; [1-(4-chloro-benzoyl)-5-methoxy-2-methyl-indol-3yl]-acetic acid methyl ester

Recent studies have reported that gastric, colon and other carcinogenic processes could be blocked by non-steroidal anti-inflammatory drugs (NSAIDs), through the inhibition of cyclooxygenase 2 (COX 2). ${ }^{1)}$ Moreover, NSAIDs, such as celebrex, sulindac, indomethacin, and others, could induce apoptosis in tumor cells and act similarly to anticancer drugs. ${ }^{1-5)}$ Indomethacin is a well-known NSAID acting as a non-selective cyclooxygenase inhibitor, which is capable of inducing apoptosis in small-cell lung cancer and gastric cancer cells. ${ }^{3-5}$ ) These facts imply that NSAIDs may be good lead compounds for inducing chemopreventive effects. In a previous study, the ester and $\gamma$-lactone derivatives of indomethacin were found through a photo-irradiated process. ${ }^{6}$ ) In this paper, the anti-inflammatory effects of indomethacin derivatives in LPS-stimulated RAW 264.7 cells and the cytotoxic effects in HL-60 cells were explored in efforts to discover new and potent chemopreventive agents.

Nitric oxide (NO) induces mutagenesis and carcinogenesis through damaging DNA bases, and also has inflammatory effects such as enhancing COX activity, etc. ${ }^{7,8)}$ Macrophages play major roles in inflammation, which can be activated by inducible nitric oxide synthase (iNOS) and COX 2 protein, and by the release of $\mathrm{NO}$ and prostaglandin $\mathrm{E}_{2}\left(\mathrm{PGE}_{2}\right)$ by lipopolysaccharide (LPS), an endotoxin. ${ }^{9)}$ Therefore, the NO and $\mathrm{PGE}_{2}$ levels of LPS-stimulated murine macrophage RAW 264.7 cells are used as indicators of carcinogenesis and inflammation.

The human promyelocytic leukemia cell line, HL-60, is usually used to detect the antitumor effects of new candidate compounds in in vitro cytotoxicity assays. Cell death can generally occur by either of two distinct mechanisms, necrosis or apoptosis. ${ }^{10)}$ Necrosis is the pathological process which occurs when cells are exposed to a serious physical or chemical insult. Apoptosis is the physiological process by which unwanted or useless cells are eliminated during development and other normal biological processes. ${ }^{10)}$ Anticancer drugs can induce apoptosis in tumor cells, and this may decrease the side effects in patients. Consequently, compounds that can induce apoptosis in tumor cells with good potency are considered to be antitumor candidate drugs. In this paper, the cytotoxic effects of test samples were measured using the MTT assay, and the active components inducing apoptosis in leukemia cells were determined by biochemical analysis.

\section{MATERIALS AND METHODS}

Chemicals and Cells Dimethyl sulfoxide (DMSO), MTT [3-(4,5-dimethylthiazol-2-yl)-2,5-diphenyl-tetrazolium bromide], LPS (Escherichia coli serotype 0127-8B), and other chemicals were purchased from Sigma Chemical (St. Louis, MO, U.S.A.). Dulbecco's modified Eagle medium (DMEM), RPMI 1640, fetal bovine serum (FBS), antibiotics, and L-glutamine were purchased from Gibco BRL (Grand Island, NY, U.S.A.). The murine macrophage cell line, RAW 264.7, and the promyelocytic leukemia cell line, HL-60, were obtained from American Type Cell Culture (ATCC; Rockville, MD, U.S.A.).

Sample Preparation Indomethacins and its photo-syn-

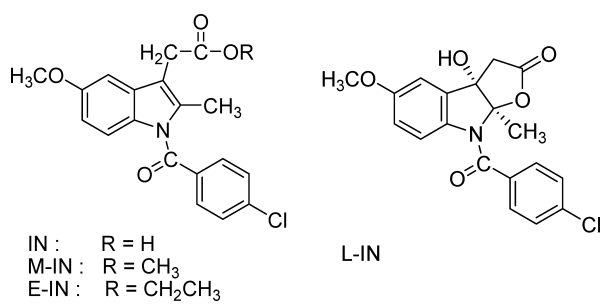

Fig. 1. Structures of Indomethacin and Its Derivatives

IN, 1-(4-chloro-benzoyl)-5-methoxy-2-methyl-indol-3-acetic acid; M-IN, [1-(4chloro-benzoyl)-5-methoxy-2-methyl-indol-3-yl]-acetic acid methyl ester; E-IN, [1-(4chloro-benzoyl)-5-methoxy-2-methyl-indol-3-yl]-acetic acid ethyl ester; L-IN, 8-(4chloro-benzoyl)-3a-hydroxy-5-methoxy-8a-methyl-2-oxo-2,3,3a,8a-tetrahydro- $1 \mathrm{H}$-furo$[2,3-b]$ indole. 
thesized products, methyl ester, ethyl ester and $\gamma$-lactone derivatives of indomethacin, were obtained from the College of Pharmacy, TMU. ${ }^{6}$ Test sample solutions of indomethacin and its derivatives $(20 \mathrm{mg} / \mathrm{ml})$ were prepared by dissolving each compound in DMSO, and then storing them at $-20^{\circ} \mathrm{C}$ until use. Serial dilutions of the sample solutions with culture medium were prepared immediately before the in vitro assays were performed. The final concentration of DMSO was adjusted to $0.5 \%(\mathrm{v} / \mathrm{v})$.

LPS-Stimulated RAW 264.7 Cells Treated with Test Samples The murine macrophage cell line, RAW 264.7, was cultivated in DMEM supplemented with 10\% FBS at $37^{\circ} \mathrm{C}$ in a humidified atmosphere of $5 \% \mathrm{CO}_{2}$. RAW 264.7 cells $\left(4 \times 10^{5}\right.$ cells $\left./ \mathrm{ml}\right)$ were plated in 96-well plates and treated with LPS $(500 \mathrm{ng} / \mathrm{ml})$ and the test samples. After $18 \mathrm{~h}$, the levels of nitrite and $\mathrm{PGE}_{2}$ in the cell culture supernatants and cell viability were measured as described below.

Measurement of Nitrite Formation Nitrite, as an indicator of NO synthesis, was determined in cell culture supernatants by the Griess reaction. The Griess reagent is composed of $1 \%$ sulfanilamide and $0.1 \%$ naphthyl ethylene diaminedihydrochloride in $5 \% \mathrm{H}_{3} \mathrm{PO}_{4}$. Supernatants $(0.1 \mathrm{ml})$ of the culture media were added to a solution of $0.1 \mathrm{ml}$ Griess reagent to form a purple azodye. Nitrite production was measured by an absorption reading at $530 \mathrm{~nm}$.

Measurement of $\mathbf{P G E}_{2}$ Production One hundred microliters of supernatant of culture medium was collected for the determination of $\mathrm{PGE}_{2}$ concentrations with an ELISA kit (Amersham Pharmacia Biotech, U.K.).

Cell Viability Mitochondrial respiration, an indicator of cell viability, was assayed by the mitochondrial-dependent reduction of MTT to formazan. Cells in 96-well plates were incubated with MTT $(0.25 \mathrm{mg} / \mathrm{ml})$ for $4 \mathrm{~h}$. Cells were solubilized in $0.04 \mathrm{~N} \mathrm{HCl}$ in isopropanol. The extent of the reduction was measured by the absorbance at $600 \mathrm{~nm}$.

Agarose Gel Electrophoresis HL-60 cells $\left(1 \times 10^{6}\right.$ cells/ well) were treated with test samples for $12 \mathrm{~h}$, and the extent of DNA fragmentation was assessed by $1.5 \%$ agarose gel electrophoresis. ${ }^{11)}$

Flow Cytometric Analysis After appropriate treatment, HL-60 cells $\left(5 \times 10^{5}\right.$ cells/well $)$ were harvested by centrifugation and washed with PBS. Cells were fixed in ice-cold $80 \%$ ethanol, treated with $1.0 \mathrm{mg} / \mathrm{ml}$ RNase A, and stained with $50 \mu \mathrm{g} / \mathrm{ml}$ propidium iodide. Samples were run through a FACScan (Becton Dickinson, San Jose, CA, U.S.A.). Results are presented as the number of cells versus the amount of DNA as indicated by the intensity of fluorescence. ${ }^{11)}$

iNOS and COX 2 Protein Expression in RAW 264.7 Cells RAW 264.6 cells $\left(4 \times 10^{5}\right.$ cells $\left./ \mathrm{ml}\right)$, grown in 6-well plates to confluence, were incubated with or without LPS, in the absence or presence of the test samples, for $18 \mathrm{~h}$, respectively. Cells were washed with ice-cold phosphate-buffered saline and stored at $-70^{\circ} \mathrm{C}$ until further analysis. Protein samples were prepared and resolved by denaturing SDSPAGE using standard methods. The proteins were transferred to a nitrocellulose membrane, and Western blotting was performed using a polyclonal rabbit IgG antibody against iNOS (sc-651), a polyclonal goat IgG antibody against COX 2 (sc$1745)$, and monoclonal mouse IgM antibody against $\alpha$-tubulin (sc-8035; all three from Santa Cruz Biotechnology, Santa Cruz, CA, U.S.A.);. Goat anti-rabbit, goat anti-mouse, or donkey anti-goat antibodies conjugated to alkaline phosphatase (sc-2007, sc-2022, and sc-2008) and BCIP/NBT (BCIP/NBT, Gibco) were used to visualize the protein bands. $^{11)}$

PARP and Caspase 3 Protein Expression in HL-60 Cells HL-60 cells $\left(5 \times 10^{5}\right.$ cells/well $)$ exposed to test samples for $12 \mathrm{~h}$ were collected into tubes and then washed with PBS. Protein samples were analyzed as described above. Western blotting was performed using an antibody specific to human poly(ADP-ribose)polymerase (PARP) (Santa Cruz Biotechnology). Goat anti-rabbit or anti-mouse antibody was conjugated to alkaline phosphatase (sc-2007; Santa Cruz Biotechnology). ${ }^{11)}$

\section{RESULTS}

The Anti-inflammatory Effects of the Methyl Ester Derivative of Indomethacin in LPS-Stimulated RAW 264.7 Cells The anti-inflammatory effects of indomethacin and its derivatives were measured by on LPS-stimulated RAW 264.7 cell model. M-IN more potently inhibited NO production by LPS-stimulated RAW 264.7 cells than did the others at $50 \mu \mathrm{g} / \mathrm{ml}$, and its $\mathrm{IC}_{50}$ value was $14.6 \mu \mathrm{g} / \mathrm{ml}$ (Table 1). In addition, the $\mathrm{PGE}_{2}$ level was also inhibited by M-IN as well as by indomethacin, but L-IN had no effect (Table 1) at $25 \mu \mathrm{g} / \mathrm{ml}$. None of the four samples showed any cytotoxicity to LPS-stimulated RAW 264.7 cells after treatment for $24 \mathrm{~h}$ at $100 \mu \mathrm{g} / \mathrm{ml}$. The effects of M-IN on the induction of iNOS and COX 2 enzyme expressions were evaluated using a Western blot technique. As shown in Fig. 2, M-IN concentration-dependently reduced the induction of iNOS and COX-2 at $12.5-100 \mu \mathrm{g} / \mathrm{ml}$ (Fig. 2). The pharmacological functions of the photo-synthesized product, M-IN, still showed anti-in-

Table 1. Effects of Indomethacin and Its Derivatives on $\mathrm{NO}$ and $\mathrm{PGE}_{2}$ Production after LPS Stimulation of RAW 264.7 Cells

\begin{tabular}{lccc}
\hline \hline & \multicolumn{2}{c}{ Inhibitory effects on NO production } & \\
\cline { 2 - 3 } Sample & $\begin{array}{c}\text { NO production } \\
\text { inhibition }^{a}(\%)\end{array}$ & $\mathrm{IC}_{50}$ inhibition \\
& & & $(\mu \mathrm{g} / \mathrm{ml})$ \\
& $34.9 \pm 2.4$ & & \\
\hline IN & $36.9 \pm 0.2$ & - & $100.0 \%$ \\
E-IN & $71.1 \pm 0.2$ & $14.6 \pm 0.3$ & $92.0 \%$ \\
M-IN & $24.6 \pm 4.1$ & - & $100.0 \%$ \\
L-IN & & & $11.0 \%$ \\
\hline
\end{tabular}

a) Concentrations of test samples were $50 \mu \mathrm{g} / \mathrm{ml}$, and cytotoxicity indexes were all less than $10 \%$. $b$ ) Concentrations of test samples were $12.5 \mu \mathrm{g} / \mathrm{ml}$. - , the $\mathrm{IC}_{50}$ of the test sample exceeded $100 \mu \mathrm{g} / \mathrm{ml}$. Results are expressed as the mean \pm S.D. of three experiments.

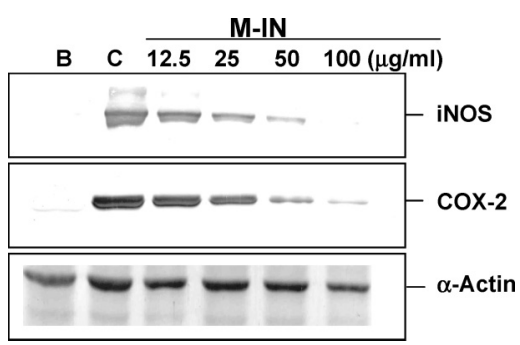

Fig. 2. iNOS and COX-2 Expression from LPS-Activated RAW 264.7 Cells Treated with M-IN

$\mathrm{B}$ indicates no treatment with LPS; C indicates the $0.05 \%$ DMSO-treated group in the presence of LPS. 


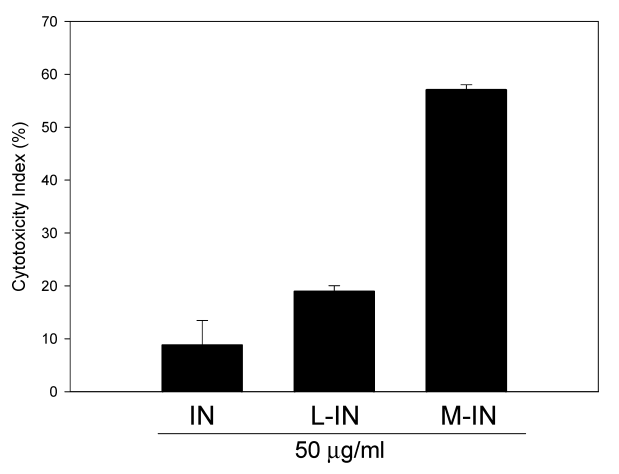

Fig. 3. Cytotoxic Effects Data Were Used from Three Separate Experiments, One of Whose Picture Is Shown

Data were used from three separate experiments.

Table 2. $\mathrm{IC}_{50}$ Values of Indomethacin and Its Derivatives in HL-60 Cells for $12 \mathrm{~h}$

\begin{tabular}{lc}
\hline \hline Sample & $\mathrm{IC}_{50}(\mu \mathrm{g} / \mathrm{ml})$ \\
\hline $\mathrm{IN}$ & $>100$ \\
$\mathrm{E}-\mathrm{IN}$ & - \\
$\mathrm{M}-\mathrm{IN}$ & 36.9 \\
L-IN & 80.2 \\
\hline
\end{tabular}

—, the test sample showed no cytotoxicity to HL-60 cells.

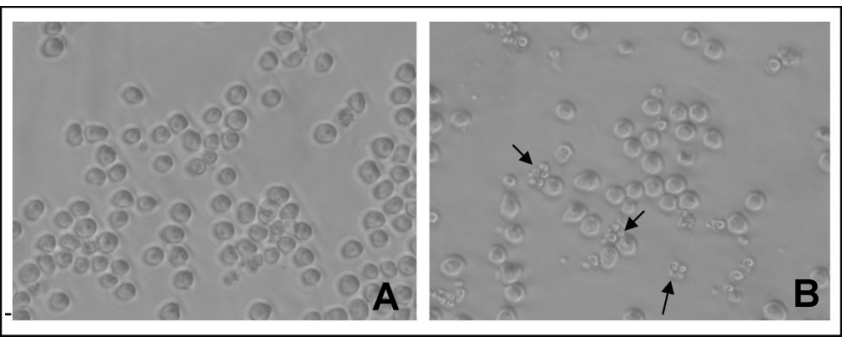

Fig. 4. Morphology of M-IN Treated HL-60 Cells

HL-60 cells were treated with solvent (A) and M-IN at $25 \mu \mathrm{g} / \mathrm{ml}$ (B) for $12 \mathrm{~h}$. The arrow indicates apoptotic bodies.

flammatory effects, as did indomethacin, and stronger effects in inhibiting iNOS and NO production by LPS-stimulated RAW 264.7 cells.

The Methyl Ester Derivative of Indomethacin Induces Apoptosis in HL-60 Cells When human leukemia HL-60 cells were treated with indomethacin and its derivatives for $12 \mathrm{~h}$ at $50 \mu \mathrm{g} / \mathrm{ml}$, cytotoxic activities were observed in the MTT assay. M-IN exhibited greater cytotoxic effects than did the others (Fig. 3), and the $\mathrm{IC}_{50}$ value was $36.9 \mu \mathrm{g} / \mathrm{ml}$ (Table 2).

To characterize the cell death of HL-60 cells, we further observed morphological changes in cells detailed using a light microscope. Several apoptotic bodies were induced in HL-60 cells after treatment with $25 \mu \mathrm{g} / \mathrm{ml}$ of M-IN for $12 \mathrm{~h}$ (Fig. 4). Apoptotic bodies have identical morphology and are known to reflect sequential stages of apoptosis. DNA fragmentation is also a characteristic feature of apoptosis. A typical experimental result of agarose gel electrophoresis is shown in Fig. 5. Increased DNA fragmentation was apparent in HL-60 cells treated with indomethacin and its derivatives for $12 \mathrm{~h}$, and M-IN showed dose dependence, while the other

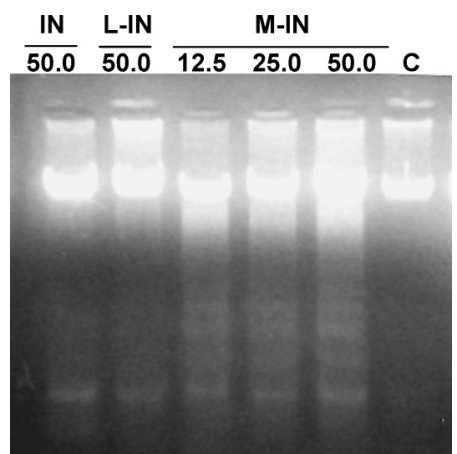

Fig. 5. DNA Fragmentation of HL-60 Cells Treated with Indomethacin and Its Derivatives for $12 \mathrm{~h}$

C, solvent control ( $0.5 \%$ DMSO). Data were used from three separate experiments, one of whose picture is shown.

did not. Apoptotic cells with degraded DNA, mostly located below the $\mathrm{G}_{1}$ peak in the DNA histogram (M1), were estimated from Fig. 6 to be $11.36 \pm 2.14 \%$ in control cells, while the percentage of apoptotic cells increased in a dose-dependent manner for $12 \mathrm{~h}$. Cell apoptosis by M-IN was also confirmed by flow cytometric analysis of DNA-stained cells. On the other hand, caspase 3 is primarily responsible for the cleavage of PARP $(116 \mathrm{kDa})$ during cell death, which produces an $89-\mathrm{kDa}$ fragment, detectable by Western blot assay. When HL-60 cells were treated with M-IN for $12 \mathrm{~h}$, the 116$\mathrm{kDa}$ band activity progressively diminished, while the 85 $\mathrm{kDa}$ signal increased dose-dependently, and that of pro-caspase 3 was reduced (Fig. 7). Moreover, the cytotoxic effects of M-IN $(25.0 \mu \mathrm{g} / \mathrm{ml})$ significantly decreased dependent on the concentration of caspase 3, when HL-60 cells were pretreated with a caspase 3 inhibitor at $12.5-100 \mu \mathrm{g} / \mathrm{ml}$ for $2 \mathrm{~h}$ (Fig. 8). From the above results, M-IN-induced apoptosis in HL-60 cells is suggested to occur through the caspase 3 pathway.

\section{DISCUSSION}

The pharmacological effects of NSAIDs reduce $\mathrm{PGE}_{2}$ levels via inhibition of COX activity or iNOS. In addition, epidemiological and laboratory studies have suggested that NSAIDs are chemopreventive for colon cancer. ${ }^{12)}$ However, only a few analgesic NSAIDs, such as lornoxicam and indomethacin can inhibit both iNOS and COX. ${ }^{13)}$ NO formation is increased during inflammation, and several classic inflammatory symptoms are reversed by NOS inhibitors, such as erythema, vascular leakiness, etc. ${ }^{7)}$ Therefore, NSAIDs can both inhibit $\mathrm{NO}$ and $\mathrm{PGE}_{2}$ production, and produce antiinflammatory and anticarcinogenic effects. In this paper, we first determined the inhibition of NO production and iNOS expression by M-IN in LPS-stimulated RAW 264.7 cells.

M-IN can be produced by the photolysis of indomethacin in methanol ${ }^{6)}$ and by other chemical syntheses. ${ }^{14)}$ Previous studies showed that selective COX 2 inhibition was improved by conversion of the free carboxylate group in indomethacin. ${ }^{14)}$ For example, E-IN and M-IN are more-significantly selective for COX 2 inhibition than is IN. ${ }^{14)}$ However, NO production from LPS-stimulated RAW 264.7 cells and the induction of apoptosis in HL-60 cells differed between M-IN and E-IN (Fig. 5, Table 2). According to our findings, 

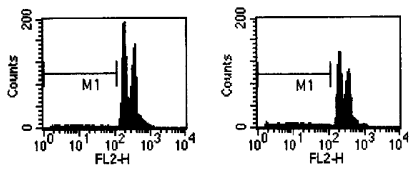

Control

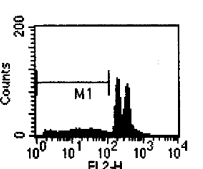

12.5
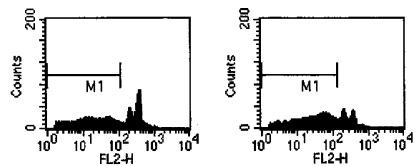

25.0
50.0

$\mathrm{M}-\mathrm{IN}(\mu \mathrm{g} / \mathrm{ml})$

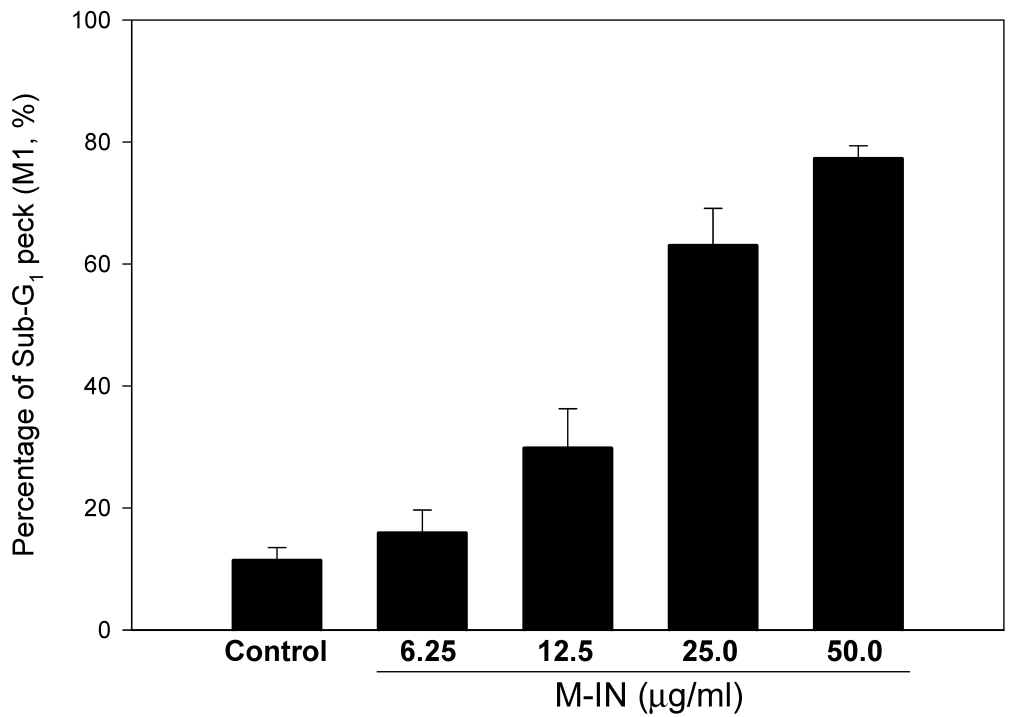

Fig. 6. Frequency Histograms of DNA Content of HL-60 Cells after Treatment with M-IN for $12 \mathrm{~h}$

$\mathrm{C}$, solvent control (0.5\% DMSO). Data were used from three separate experiments, one of whose picture is shown.

$\frac{M-I N}{6.2512 .5}$

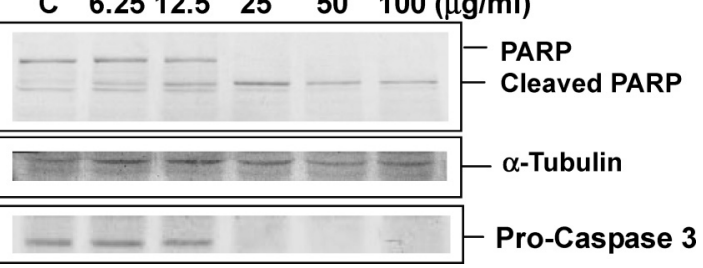

Fig. 7. Western Blot Analysis of PARP, Caspase 3, and $\alpha$-Tubulin Proteins in M-IN-Treated HL-60 Cells for $12 \mathrm{~h}$

$\mathrm{C}$, solvent control ( $0.5 \%$ DMSO). $\alpha$-Tubulin was used as an internal control to identify equal amounts of protein loading in each lane. Data were used from three separate experiments, one of whose picture is shown.

M-IN inhibited the $\mathrm{PGE}_{2}$ level as well as IN and the effects of iNOS and COX 2 expression from LPS-stimulated RAW 264.7 cells (Table 1, Fig. 2), but E-IN and IN did not. Furthermore, M-IN induced cytotoxicity in HL-60 cells with an $\mathrm{IC}_{50}$ value less than that of IN (Table 2), and induced apoptotic bodies and DNA fragmentation (Figs. 4-6). Results indicated that M-IN induced apoptosis in HL-60 cells. PARP is involved in DNA repair and genomic integrity. ${ }^{10,15)}$ When PARP is cleaved to an $86-\mathrm{kDa}$ fragment, the DNA repair function is inhibited. ${ }^{10,15)}$ The active form of caspase 3 is a 17-kDa fragment, which directly cleaves PARP during apoptosis. $^{10,16)}$ In Fig. 7, M-IN is shown to enhance the cleavage of PARP and decrease Pro-caspase $3(32 \mathrm{kDa})$ expression in HL-60 cells after treatment for $12 \mathrm{~h}$. On the other hand, the cytotoxic effect of M-IN was significantly recovered by cotreatment with a caspase 3 inhibitor (Fig. 8); therefore

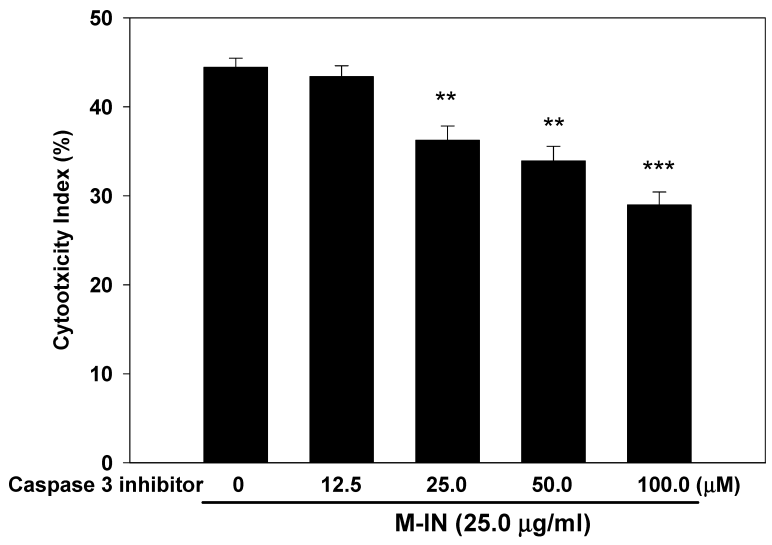

Fig. 8. Cytotoxic Effects of M-IN Cotreated with a Caspase 3 Inhibitor for $12 \mathrm{~h}$

Data were used from three separate experiments. Statistical analysis was performed using an unpaired Student's $t$-test. ** $p<0.005$ and $* * * p<0.005$.

apoptosis is suggested to occur through activation of caspase 3 .

The structure of indomethacin's methyl ester is different from indomethacin that is methyl ester and may be hydrolysis by esterase of cells and releases $\mathrm{MeOH}$. However, if methyl ester of indomethacin $(100 \mu \mathrm{g} / \mathrm{ml})$ is complete hydrolysis, only $0.269 \mathrm{~mm} \mathrm{MeOH}$ will be released. When HL60 cells were treated $0.5 \% \mathrm{MeOH}(123.4 \mathrm{~mm})$, no cytotoxicity was induced. Therefore, we suggested the cytotoxicity effect of methyl ester of indomethacin is not caused via $\mathrm{MeOH}$. In summary, when the free hydroxyl group of in- 
domethacin (IN) was changed to methyl ester (M-IN), the subsequent pharmacological effects differed. However, M-IN exhibited greater effects as a chemopreventive and anti-inflammatory drug than IN, a NSAID.

\section{REFERENCES}

1) Presott S. M., Fitzpatrick F. A., Biochim. Biophys. Acta/Reviews on Cancer, 1470, M69-M78 (2000).

2) Lim J. T. E., Piazza G. A., Han E. K. H., Delohery T. M., Li H., Finn T. S., Buttyan R., Yamamoto H., Sperl G. J., Brendel K., Gross P. H., Pamukcu R., Weinstein I. B., Biochem. Pharmacol., 58, 1097-1107 (1999).

3) Zhu G. H., Wong B. C. Y., Eoog M. C., Ching C. K., Yuen S. T., Chan E. Y. T., Lai K. C., Lam S. K., Br. J. Cancer, 79, 393-400 (1999).

4) Zhou X. M., Wong B. C., Fan X. M., Zhang H. B., Lin M. C., Kung H. F., Fan D. M., Lam S. K., Carcinogenesis, 22, 1393-1397 (2001).

5) de Groot D. J., Timmer T., Spierings D. C. J., Le T. K. P., de Jong S., de Vries E. G., Br. J. Cancer, 92, 1459-1466 (2005).

6) Wu A. B., Cheng W. H., Hu C. M., Chen F. A., Chou T. C., Chen C.Y.,
Tetrahedron Lett., 38, 621-622 (1997).

7) Cochran F. G., Selph J., Sherman P., Med. Res. Rev., 16, 547-563 (1996).

8) Wink D. A., Kasprzak K. S., Maragos C. M., Elespuru R. K., Misra M., Dunams T. M., Allen J. S., Keefer L. K., Science, 254, 10011002 (1991).

9) Heitmeier M. R., Scarim A. L., Corbett J. A., J. Biol. Chem., 273, 15301-15307 (1998).

10) Allen R. T., Hunter III W. J., Agrawal D. K., J. Pharmacol. Toxicol. Meth., 37, 215-228 (1997).

11) Wang C. C., Chen L. G., Yang L. L., Cancer Lett., 149, 77-83 (2000).

12) Williams C. S., Mann M., Dubois R. N., Oncogene, 18, 7908-7916 (1999).

13) Berg J., Fellier H., Christoph T., Grarup J., Stimmeder D., Inflamm. Res., 48, 369-379 (1999).

14) Kalgutkar A. S., Marnett A. B., Crews B. C., Remmel R. P., Marnett L. J., J. Med. Chem., 43, 2860-2870 (2000).

15) Decker P., Muller S., Curr. Pharm. Biotechnol., 3, 275-283 (2002).

16) Concha N. O., Abdel-Meguid S. S., Curr. Med. Chem., 9, 713-726 (2002). 